\title{
INTERNATIONAL HEALTH IN THE LIGHT OF NATIONAL HEALTH ACT IN
} NIGERIA; THE CRITICAL ISSUES

\author{
Ogbonna Brian $\mathrm{O}^{1 *}$, Uzodinma Samuel $\mathbf{U}^{2}$, Okwuosa Ogechukwu $\mathrm{L}^{2}$ \\ "E-mail: bo.ogbonna@unizik.edu.ng; +2348037794206 \\ *1,2 Department of Clinical Pharmacy and Pharmacy Management, Faculty of Pharmaceutical Sciences, Nnamdi \\ Azikiwe University Awka, Nigeria \\ ${ }^{3}$ Chukwuemeka Odimegwu Ojukwu University Teaching Hospital, Amaku Awka, Nigeria
}

*Corresponding Author: -

E-mail: bo.ogbonna@unizik.edu.ng +2348037794206

\begin{abstract}
: -
Treaties and rapid developments in science integrate nations, and advances in technology have reduced the world into a global village. With an estimated seven billion global population coupled with high human traffic and movement of goods and services across borders, nations have been at increased risk of disease outbreak and epidemics across borders which necessitated for disease surveillance, prevention, management and control through corporation between nations at the borders. With the introduction of the national health act in Nigeria in 2014, the federal ministry of health was charged with the responsibility of ensuring and promoting the provision of Quarantine and Port Health Services. This article assessed the fundamental issues in successful port health services.
\end{abstract}

Keywords: - international health, port health, health act, borders, quarantine, Nigeria

\section{(a) $(\$)$}




\section{INTRODUCTION}

International health is, "A health activity involving persons, communities, and/or institutions in two or more countries". In view of the fact that epidemic diseases move across borders coupled with the ever-increasing wave of globalization, there arose the need to stimulate International Corporation to promote global health. After the first international sanitary conference in Paris in 1851- 1852, diseases like plague, cholera and other epidemic outbreak were controlled by international agreement in 1903. Pan American sanitary bureau of 1902, which coordinated quarantine procedures, underwent series of metamorphosis until 1950 when all people of the world the highest level of health took it over by WHO to promote attainment. Following the birth of WHO on April 71948 as the police of the health of nations, she was saddled with the responsibility of prevention and control of diseases using epidemiological data, development of comprehensive health services, promotion of family and environmental health. Other duties include provision of health statistics, health information and literature, prevention and control of tropical diseases, international collaboration with specialized agencies, promotion of research and development globally among others. This article assessed the fundamental issues in successful port health services. ${ }^{[1,2,11]}$

\section{Globalization, travel medicine, and health}

The WHO through the concept of international basic travel medicine provides information and the necessary immunization coverage required to embark on a journey to such places. They provide the necessary conditions that must be strictly adhered to, for travelers entering or leaving a country. They listed the diseases under international surveillance egg plague, cholera, typhus, yellow fever, and louse-borne relapsing fever. Among these five diseases, plague, yellow fever, and cholera were listed as diseases under international quarantine law. The concept of international health has proven that airports, seaports, and land borders are potential corridors for especially for infectious diseases, which pose hazards and threats to nations. It underscored the need for strict scrutiny of all people crossing international boarders through emigration and immigration to ensure security of lives and prevent the outbreak of diseases, which are preventable.

Individuals suspected to be ill or contaminated from disease causing organisms are quarantined for specified period, which depend on the incubation period of the organism or condition involved. Ship captains are expected to present exemption or de-rating certificates while passengers are expected to present their international vaccination certificates. Where all the conditions have been truly certified and proven okay, the ship can fly the ' $L$ ' or yellow flag for access, the captain can request for a Pratique or permission to dock with rat guard, and all the necessary procedures carried out. However, where the ship is suspected to be contaminated or carrying an ill person, it is expected to fly the double yellow flag, which denotes an infected ship. It must be moved to a mooring zone where it must be thoroughly scrutinized and inspected by port health officers and no passenger is expected to leave the ship until the exercise is completed. When a ship is infected, the necessary steps involved in isolation, re-vaccination, surveillance, disinfection, notification and quarantine must be strictly adhered to as a way of quality control and assessment.

Health officers at the international airport are expected to vaccinate all passengers coming from infected ports who have not met the necessary immunization requirements. Passengers should be placed under surveillance where necessary. Aircraft coming from infected regions should be inspected for the disease vectors and the necessary disinfection carried out with the right agent. Toilet wastes are sent to lab for necessary investigations to ensure adequate disinfection. Sampling of food, water, restaurants, and other necessary items for contaminants. Passengers and crew members with minor ailment should be treated promptly. Port health workers and officials should ensure that all these activities and meticulously carried out and the necessary documentations obtained and very timely too in line with WHO international health regulations.

[4,5]

.In 1925, the Nigerian port health services commenced operations under public health department of the federal ministry of health $(\mathrm{FMOH})$ in line with the international health regulations and upholding the Nigerian Quarantine Act. The national health act of Nigeria charged the FMOH with the responsibility of ensuring and promoting the provision of Quarantine and Port Health Services covering the air, land, and sea borders. This noble task is achievable with the concerted efforts of relevant stakeholders. Strengthening of disease surveillance and notification unit of the port health services is key to effective prevention and control of disease movement across borders. Availability of necessary vaccines for immunization and administration of booster doses where necessary is very essential. The out-of-stock syndrome must never be allowed at any point. This calls for sound drug supply management. Standard measures should be adopted in issuance and certification of international health certificates egg Yellow cards. Strict compliance to procedures in barding of aircrafts, ship and vehicle inspection at the sea and land boarders should never be compromised. Quality control procedures should be put in place with global best practices, which should be standardized periodically. Adequate staffing should be encouraged to enable proper coverage during rush seasons and disasters.

Port health services should uphold uttermost environmental health geared towards sanitation, proper waste disposal, control of pollution, control of vectors and all forms of contaminants. Disinfection, of vessels, cabins, surfaces and passengers; decontamination of conveyances, vector clearance and deratting should be monitored at all levels and proper documentations made. A comprehensive framework should be in place for preventive and curative health care and comprehensive health structure for admission, referral and miscellaneous services and operations. We need to scale up our approach to health. ${ }^{[6,9]}$

\section{Accessing technologies in service}

Adequate budget is very essential to enable system upgrade and procurement of state of the art facilities for patient data capture and correspondence with existing database within and outside the country. Relevant technologies will assist in contact with relevant organizations within and outside the ports, update, follow- up and tracking of passengers, contact 
tracing, personnel mobilization and routing of infected passengers in line with global best practices. The use of relevant technologies will facilitate timely dissemination of information to relevant state holders, establishment of contacts and timely sharing of information with relevant hospitals and agencies, timely screening of passengers on arrival and departures, rapid epidemiological response and prompt sharing and use of data for decisions and interventions. In recent times, use of adequate technologies in prompt and rapid detection and assessment of disinfection status of wide range of surfaces of passengers, goods, cabins and equipment and helps to keep human errors at the barest minimum. Regular recruitment of relevant personnel, provision of adequate space and facilities to aid and facilitate routine operations is necessary to keep practice and services in line with international health regulations (IHR) and global best practices.

\section{Staff training, research, and development}

Staff training is of paramount importance in smooth and efficient running of operations in the twenty-first century. Regular staff training and postings to state of the act facilities is vital in smooth running and operation of the entire facility. It encourages technology transfer and cross breed of ideas, information and technologies. It is done in collaboration with foreign agencies, organization and embassies or foreign missions. It is implemented on contract basis with reputable institutes and institutions. At the base of every sustainable program is research. It must be encouraged at all level and throughout the entire system. Research units, which can be independent of disseminated, encourage regular improvement and promotion of best practices in line with recorganized and established standards. ${ }^{[9,10,11]}$

\section{Management information systems}

Management information system forms the core of any dynamic organization. It forms the basis for generation of data, reviews, upgrade, need assessment, and evaluation of performance indicators. Good design of information system captures procedures, actions, operations, and audit trails from the positive and negative angles. There should be laminar flow of information through the information system pyramid from the operational systems which covers procurements, personnel management, financial management, distribution, use, passengers traffic dynamics and all transaction data and, trends; to scheduled and on-demand reports and management control up to the executive information for timely strategic planning. This should be without prejudice to all the necessary systems for effective and efficient data capture. Information needs of users at all levels and should be designed to alert on problems and help in forecasting with necessary information from national, district and facility levels. A good management information system should make provisions for prompt feedback, which allows for necessary amendments and timely corrections. ${ }^{[6,7,8,11]}$

\section{Conclusion}

The world is now a global village and diseases move across borders in line with the waves of globalization. Surveillance activities, system upgrade and follow up should be a continuous process not adhoc when there is signal of outbreak or during periods of anticipated high movement of passengers across borders. The culture of simple hygiene egg hand washing, use of hand sanitizers, fumigation and regular disinfection of surfaces should be promoted by the port health authority and necessary disinfectants made available continually and well budgeted. Individual nations should reorganize the need for accountability in their operations, which can help in bridging health inequities. They should foster collaborations with non-governmental organizations. The Federal Ministry of Health (FMOH) through the national health act has been mandated to ensure and promote the provision of Quarantine and Port Health Services. The issues highlighted could form the framework and road map to an efficient and dynamic port operations towards promoting sound, safe and effective port health services locally and internationally. Comprehensive supervision framework must be in place at all levels. Monitoring and evaluation should be a continual process with periodic evaluation of the indicators.

\section{Competing interest}

Authors indicated no conflict of interest

\section{References}

[1].Global Health Treaty. Accessed on April 182016 at http://www.globalhealthtreaty.org

[2].Hoffman SJ, Røttingen JA. "Dark Sides of the Proposed Framework Convention on

[3].Global Health's Many Virtues: A Systematic Review and Critical Analysis," Health \& Human Rights Journal 2013; 15(1): 117-134.

[4].The Senate, Federal Republic of Nigeria (FRN), National Health Act of Nigeria. 2014; functions of the Federal Ministry of Health.

[5].World Health Organization (WHO). International Travel and Health- Vaccination requirements and health advice. 1997; WHO, Geneva.

[6].Newell KW. Global strategies- developing a unified strategy. In: Holland WW., Detels R. and Knox G. (Eds.) Oxford Textbook of Public Health.1985; Oxford University Press, Oxford, pp. 261 - 271.

[7].Bertrand WE. Information as a primary health care intervention: The impact of technologies on improving health for all. Information technology for development. 1989; 4: 741- 49.

[8].Management Science for Health (MSH). Managing and using information. In the family planning manager's handbook: Basic skills and tools for managing family planning programs. Ed Wolf JA, Suttenfield LJ and Binzen SC. 1991; West Hartford, Conn.; Kumarian Press.

[9].Management Science for Health (MSH). Drug supply management information strategies and systems. In Managing drug supply training series. 1992; Part 3. Supply management. Boston: MSH. 
[10]. Global Forum for Health Research. Fostering innovations for global health. Global forum update on research for health. 2008; 5:63-69. Accessed on 21 March 2015 at http://www.globalforumhealth.org

[11]. Murray CJL, Lopez AD. The global burden of diseases: a comprehensive assessment of mortality and morbidity from diseases, injuries, and risk factors in 1990 and projected to 2020. Cambridge, Harvard School of Public Health on behalf of the World Health Organization and The World Bank (Global Burden of Diseases and Injury Series, Vol. 1).

[12]. Adetokumbo OL, Herbert MG. Short textbook of Public Health Medicine in the Tropics.

[13]. Ed (4) 2003; 15: pp 11- 27, 363- 374. 